\title{
Fabrication of Aluminium Base Composite by Foundry Technique
}

\author{
By V. Agarwala* and D. Dixit*
}

\begin{abstract}
In the engineering applications where the aluminium and/or aluminium alloy are in sliding contact a tendency of galling or seizing at the interface play an important role. In order to reduce this adverse effect and to develop an aluminium based bearing material, graphite particles were dispersed in $7079 \mathrm{Al}$-alloy having high strength and toughness.

The variables-speed of stirring, temperature of the melt and preheating temperature of graphite are optimized to facilitate incorporation of graphite in the melt and its subsequent solidification resulting in the desired composite. An improvement in the wear property in contact with mild steel was observed in comparison to that of the matrix alloy.
\end{abstract}

(Received December 19, 1980)

\section{Introduction}

For many engineering application it is desirable to run aluminium and/or aluminium alloys in sliding contact with each other. However, this is generally impracticable, since they tend to gall or sieze except under virtually ideal conditions. The problem becomes appreciably greater when boundary lubrication conditions exist. Various solutions to these problems are tried for many years. They include the development of surface coating, surface treatments and alloys of intrinsically high hardness. Anodizing the aluminium surface has not proved satisfactory in overcoming the seizing problem as the anodized layer rapidly wears away ${ }^{(1)}$. Although chromium plating of aluminium surface has been successful, it is expensive and calls for strict quality control.

An alternative approach was to develop a composite incorporating a solid lubricant such as graphite, in one or both of the sliding surfaces. Graphite in aluminium and aluminium alloys is found to improve appreciably the gall resistance, wear resistance and the anti-frictional properties ${ }^{(2)}$. The graphite may be incorporated in solid metals by rejection of dissolved carbon from the molten metal on solidification as in cast irons or nickel or by

* Department of Metallurgical Engineering, University of Roorkee, Roorkee-247672, India. powder metallurgy technique or by mechanical mixing of graphite in the melt at the time of casting. Greater importance is given in recent years to the foundry techniques to produce aluminium-graphite composites as they are cheaper and do not impose limitations on size and shape of the part to be produced.

Badia and Rohatgi ${ }^{(3)}$ made an effort to disperse graphite particles with and without nickel coating. Nickel coated particles were

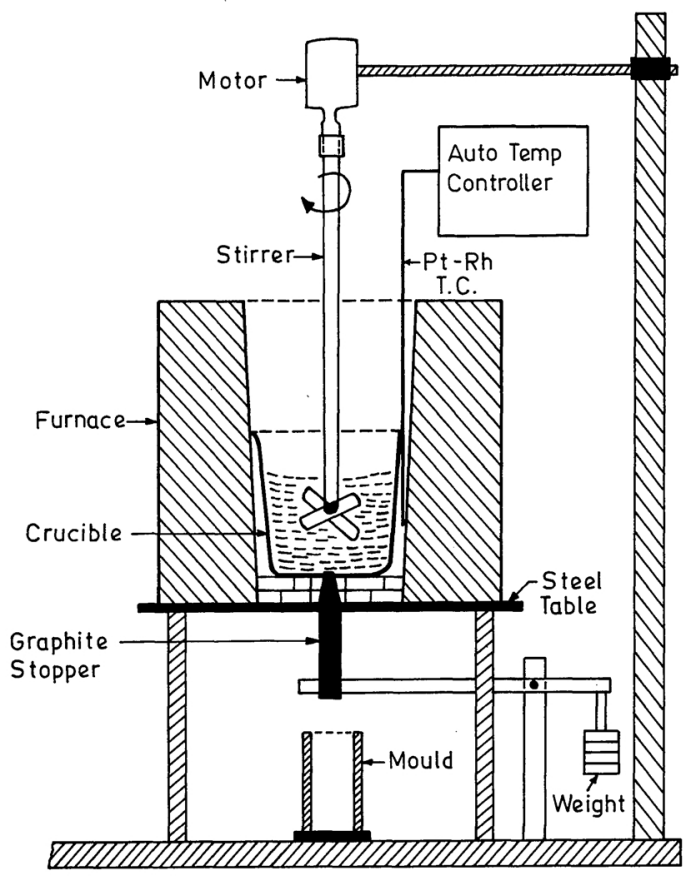

Fig. 1 Experimental set-up. 
successfully dispersed and retained where as the uncoated and pre-oxidised particles were completely rejected from the melt. It was reported $^{(4)}$ that the $\mathrm{Ni}$ coated graphite particles could be dispersed successfully in aluminium melt by master alloy technique. Badia et al. ${ }^{(5)}$ in the attempt to produce aluminium graphite composite for bearing applications introduce a new Vortex method of mechanical mixing and reported better results than gas injection method.

The scope of this work is to optimise the process variables for the fabrication of the aluminium graphite composite by means of mechanical mixing. The variables-speed of stirring temperature of melt and preheating temperature of the graphite particles are optimised to obtain the suitable composite. Bottom pouring technique was used to enhance incorporation of the graphite particles by reducing the time of pouring.

\section{Experimental Procedure}

\section{Alloy preparation}

7079 Al-alloy was chosen as the matrix for this study since this alloy has optimum strength and toughness for the bearing applications. The alloy of the following composition $0.6 \%$ $\mathrm{Cu}, 0.2 \% \mathrm{Mn}, 0.2 \% \mathrm{Cr}, 3.3 \% \mathrm{Mg}, 4.3 \% \mathrm{Zn}$ and remaining $\mathrm{Al}$, was prepared by melting the master alloys of $\mathrm{Al}-\mathrm{Mn}, \mathrm{Al}-\mathrm{Cu}$ and $\mathrm{Al}-\mathrm{Cr}$ along with the calculated amount of $\mathrm{Mg}$ and $\mathrm{Zn}$ at $1123 \mathrm{~K}$ in a muffle furnace. When the proper mixing of the elements were ensured in the melt the alloy was chill cast in a mild steel mould.

\section{Experimental procedure}

The crucible was kept in the furnace as shown in Fig. 1. When the desired temperature was reached a weighed amount of 7079 Al-alloy was added in the crucible after fixing the stopper at the bottom of the crucible. The impeller was fixed above the crucible. After they melted the preheated impeller was introduced into the melt and the speed of the stirrer was slowly raised to the desired level. Then the graphite powder (if preheated then from the preheating furnace) was added. The stirring was continued for $150 \mathrm{~s}$. Then the stopper at the bottom of the crucible was released by the lever arrangement and the composite was chill cast into the mild steel mould by bottom pouring.

\section{Specimen preparation}

The solidified castings were sliced and subsequently polished for microstructure study. The mass $\%$ of graphite retained in the alloy was determined by dissolving a weighed amount of sample in concentrated $\mathrm{HNO}_{3}$ by prolonged heating till all the reactions were complete. The undissolved particles were filtered, dried and weighed to give the amount of graphite present in that sample. To find out the wear characteristics each specimen was given three Vickers indentation of diamond pyramid at a load of $49 \mathrm{~N}$ and the diagonal of

Table 1 Size of graphite particles $<15$ mesh, amount of graphite particles $6 \%$ of the melt, time of stirring $150 \mathrm{~s}$, and time of preheating $1800 \mathrm{~s}$.

\begin{tabular}{ccccccc}
\hline \hline $\begin{array}{l}\text { Heat } \\
\text { No. }\end{array}$ & $\begin{array}{c}\text { Melt } \\
\text { temp. } \\
(\mathrm{K})\end{array}$ & $\begin{array}{c}\text { Stirring } \\
\text { speed } \\
\left(\mathrm{s}^{-1}\right)[\mathrm{rpm}]\end{array}$ & $\begin{array}{c}\text { Preheating } \\
\text { temp. }(\mathrm{K})\end{array}$ & $\begin{array}{c}\text { Mass\% } \\
\text { graphite } \\
\text { retained }\end{array}$ & $\begin{array}{c}\text { Vol\%o } \\
\text { graphite } \\
\text { retained }\end{array}$ & $D_{p}(\mu \mathrm{m})$ \\
\hline 1 & 1123 & $8.3[500]$ & No preheating & - & - & - \\
2 & 1123 & $25[1500]$ & No preheating & - & - & - \\
3 & 1123 & $50[3000]$ & No preheating & - & 5.1 & 3.25 \\
4 & 1123 & $50[3000]$ & 873 & 1.82 & 2.17 & 200 \\
5 & 1123 & $50[3000]$ & 923 & 1.3 & 1.55 & 222 \\
6 & 1123 & $50[3000]$ & 973 & 3.18 & 3.78 & 26.6 \\
7 & 1123 & $50[3000]$ & 1023 & 2.91 & 3.47 & 34.3 \\
8 & 1073 & $50[3000]$ & 873 & 2.79 & 3.33 & 53.6 \\
\hline
\end{tabular}


this indentation was measured. These samples were kept on M.S. sheet of an automatic revolving machine to give a direct metal to metal sliding contact for $1.8 \mathrm{ks}$. By knowing the decreased average diagonal of the indentation after the wear test the $\%$ mass loss of the specimens could be compared.

\section{Results}

The results of the experiments to produce Al-graphite composites by varying stirring speed, melt temperature and preheating temperature of graphite particles are shown in Table 1. To illustrate the effect of melt temperature and the preheating of graphite particles on the particle distribution, micro photographs at $60 \times$ are shown in Photos. 1 and 2.

\section{Discussion}

\section{Retention of graphite}

The mass \% graphite retained was found to decrease with decreasing temperature of the melt when stirring speed and preheating temperature of graphite particles are kept constant (Fig. 2). This may be due to the lower viscosity and surface tension of the melt at relatively higher temperatures.

The importance of the preheating in the incorporation of graphite particles can be seen from the observation that there was no particle retention when the preheating was not given to the graphite particles (heats (1-3) in Table 1). Whereas the graphite particles were retained (heats (4-7) in Table 1) when the preheating operations were conducted.

Figure 3 shows that the mass \% graphite retained decreases with increase in preheating temperature from $873 \mathrm{~K}$ to $973 \mathrm{~K}$, but above $973 \mathrm{~K}$ the trend is reversed. From the study of the oxidation of graphite it is known that graphite gets oxidised to $\mathrm{CO}_{2}$ above $753 \mathrm{~K}$. But above $973 \mathrm{~K}$ the formation of $\mathrm{CO}$ is favoured. When the preheated graphite particles are put in the melt the particles are covered by the gaseous oxidation products around its surface. The ability of the liquid melt to replace this gaseous layer depends on its wettability
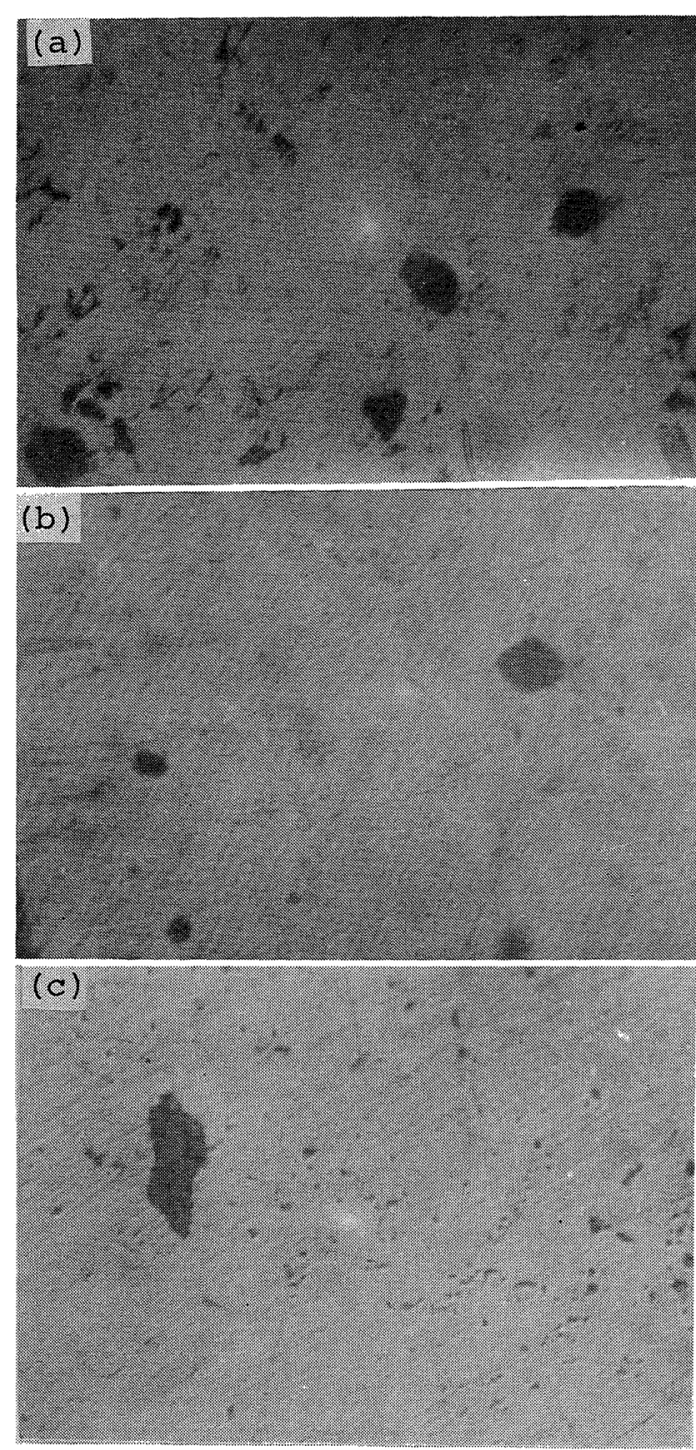

Photo. 1 Effect of melt temperature on the particle distribution in the alloy.

for the graphite particle i.e. the contact angle under that particular atmosphere. The change in the nature of the gaseous layer from $\mathrm{CO}_{2}$ to $\mathrm{CO}$ at around $973 \mathrm{~K}$ may be increasing the wettability of the particles by reducing the contact angle. As a result the graphite retention is increasing above $973 \mathrm{~K}$.

In the first three heats the graphite particles without any preheating could not be transferred to the molten alloy even by increasing the speed of the impeller to $50 \mathrm{~s}^{-1}(3000 \mathrm{rpm})$. Obviously the wettability of the particles have not been 

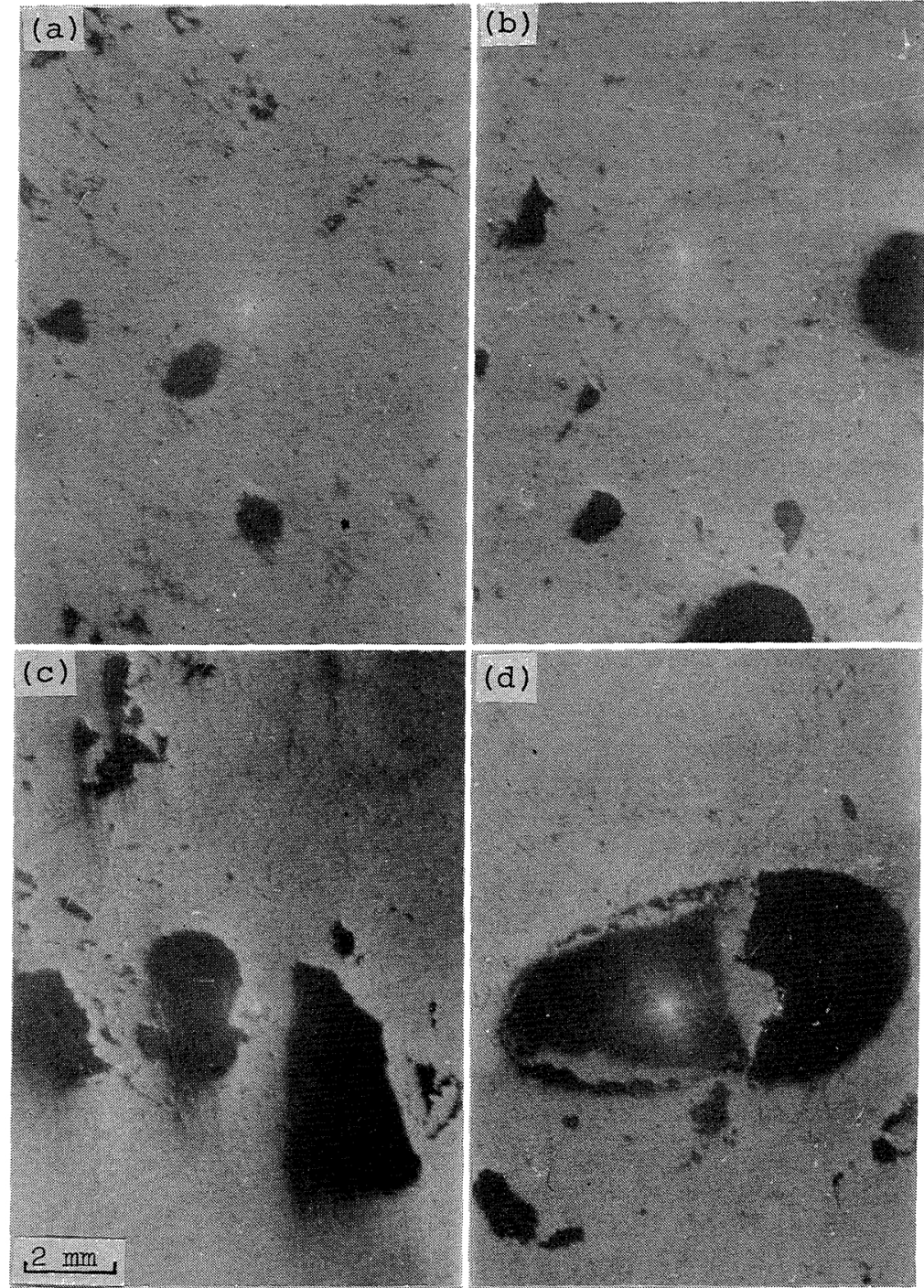

Photo. 2 Effect of preheating temperature on the particle distribution in the alloy.

enough under these circumstances because the graphite particles are surrounded by the ordinary nitrogenous atmosphere at room temperature. This atmosphere gets modified when the particles come in contact with the molten metal. Prevailing high temperature helps the oxidation of the particle by the oxygen of the air layer around it. Since the oxygen supply is limited once the particle gets into the liquid and the replacement of air has not taken place beforehand it is possible that there exists an atmosphere of $\mathrm{N}_{2}$ and $\mathrm{CO}$ which causes a lower wettability between graphite and the alloy than that obtained under majority $\mathrm{CO}$ or $\mathrm{CO}-\mathrm{CO}_{2}$.

Also, preheating results in the lowering of the density of the surrounding gas which undergoes expansion compared to the air envelop surrounding the particle at room temperature. So the buoyancy effect in the case of preheated powder may be less in comparison to that of the powders without preheating. The above two factors may be responsible for the failure to incorporate particles without preheat.

\section{Distribution of graphite}

The graphite particle distribution was microscopically observed to be more uniform 

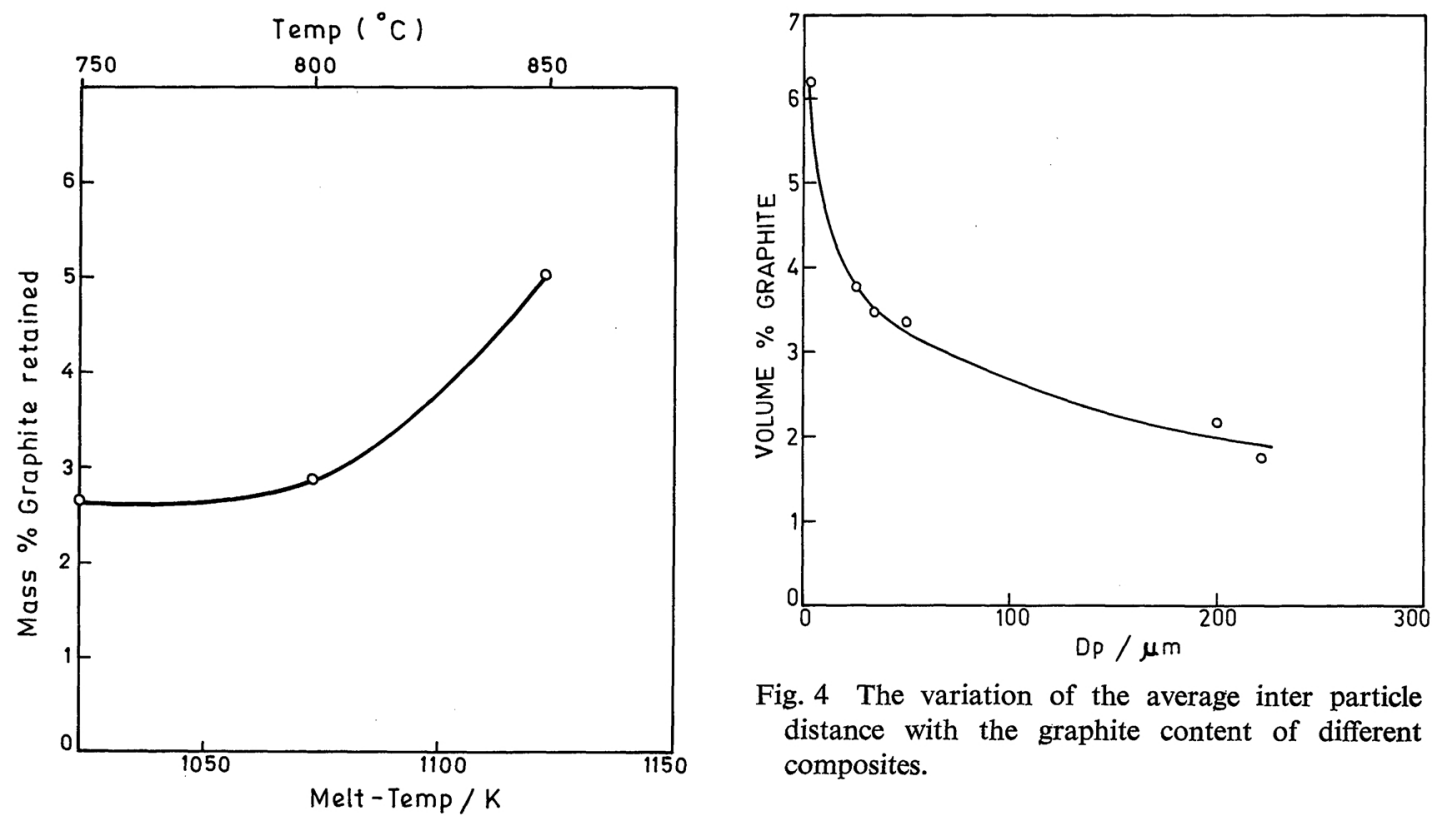

Fig. 4 The variation of the average inter particle distance with the graphite content of different composites.

Fig. 2 Effect of melt temperature on graphite particle retention.

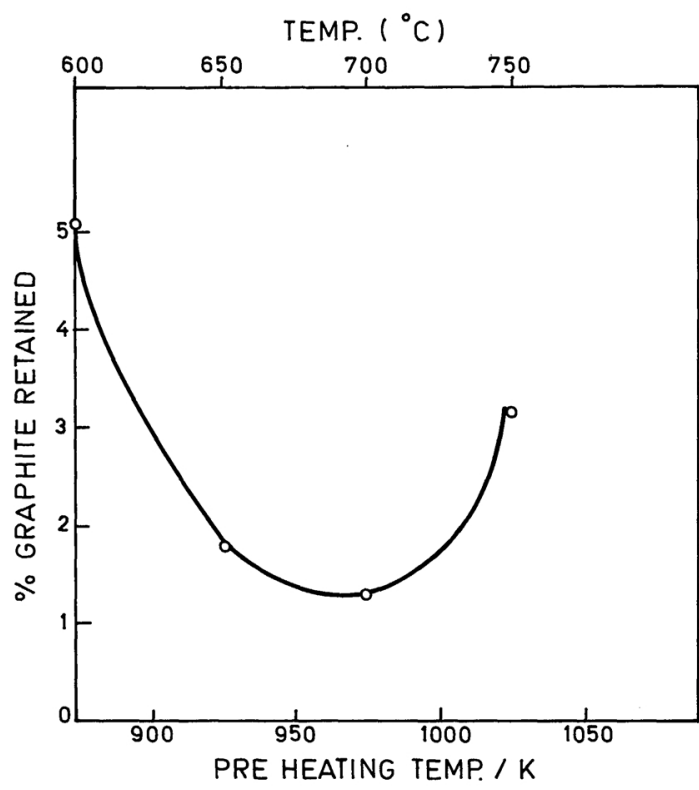

Fig. 3 Effect of preheating temperature on graphite particle retention.

at relatively higher temperatures due to the lowering of viscosity of the melt and higher convection currents resulting in uniform mixing of graphite particles in the melt (Photo. 1). The

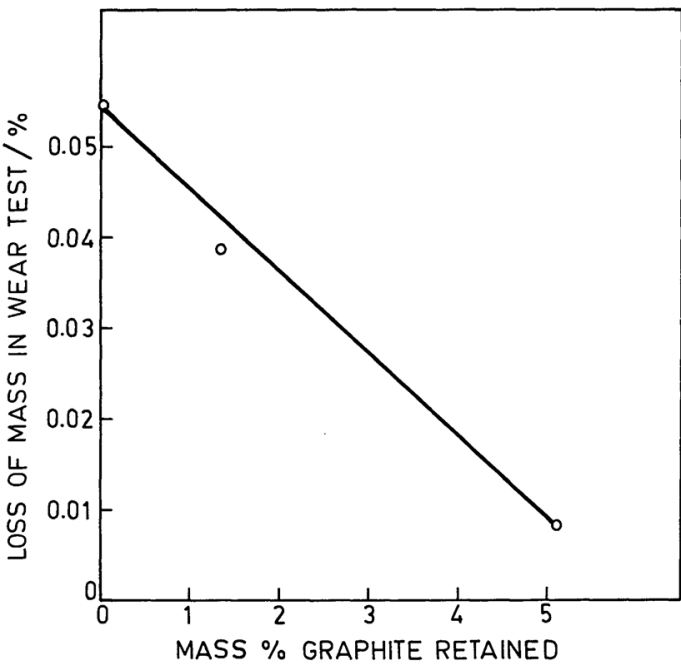

Fig. 5 The effect of graphite retention on the wear resistance of the alloy.

variation of the average inter particle distance with the graphite content of the different composites are given in Fig. 4. When the preheating temperature of the graphite powder was $873 \mathrm{~K}$ the graphite powder distribution was found to be quite uniform. As the preheating temperature increased the tendency to form an aggregate of particles enhanced resulting into bigger voids by coalescence of envelops surrounding the particles (Photo. 2). 


\section{Wear resistance of the composite}

The wear resistance of the alloys containing $5.1 \%$ and $1.82 \%$ graphite in contact with mild steel were measured and compared with 7079 Al-alloy without graphite particles. It is seen that the wear resistance of $7079 \mathrm{Al}$-alloy is the least and increases with increase in the graphite content of the alloy (Fig. 5). From this it is clear that the graphite particles act as solid lubricant in Al-alloy thereby reducing the wear loss of the specimen as the graphite content increases.

\section{REFERENCES}

(1) A. M. Pattan: J. Inst. Metals, C 100 (1972), 197.

(2) P. K. Rohtgi: Composite Material, 9 (1978), 153.

(3) F. A. Badia and P. K. Rohtgi: Trans. AFS, 77 (1969), 402

(4) B. C. Pai, S. Ray, K. V. Prabhakar and P. K. Rohtgi: Mat. Sci. Engg., 24 (1976), 31.

(5) F. A. Badia, D. F. Mc Donald and J. R. Pearson: Trans. AFS, 79 (1971), 265. 